\title{
Management of endophthalmitis while preserving the uninvolved crystalline lens
}

This article was published in the following Dove Press journal:

Clinical Ophthalmology

19 March 2012

Number of times this article has been viewed

\section{Justin Townsend \\ Avinash Pathengay \\ Harry W Flynn Jr \\ Darlene Miller}

Department of Ophthalmology, Bascom Palmer Eye Institute, University of Miami, Miller School of Medicine, Miami, FL, USA
Correspondence: Harry W Flynn Jr Bascom Palmer Eye Institute, 900 NW 17th Street, Miami, FL 33136, USA

$\mathrm{Tel}+\mathrm{I} 3053266118$

Fax + I $30532664 \mid 7$

Email hflynn@med.miami.edu
Background: The purpose of this work is to report on the management of endophthalmitis in phakic eyes in which the crystalline lens was preserved.

Methods: The current study is a noncomparative consecutive case series of patients who developed culture-proven endophthalmitis and were treated between January 1995 and June 2009. The study included only phakic patients whose infection was managed without removal of the crystalline lens. Using a computerized search of Microbiology Department records, patients were identified with phakic lens status and clinically diagnosed endophthalmitis.

Results: A total of 12 phakic eyes from 11 patients met the study criteria. The etiology of infection was endogenous $(n=6)$, postoperative $(n=5)$, and post-traumatic $(n=1)$. Pars plana vitrectomy and injection of intravitreal antimicrobials was performed in seven eyes (58\%), and vitreous tap and injection of antimicrobials was performed in five eyes (42\%). All eyes showed progression of lens opacification after treatment. Overall, nine (75\%) achieved visual acuity outcomes $\geq 20 / 80$, including five of seven (71\%) eyes treated with vitrectomy and four of five eyes (80\%) treated with injection of antibiotics alone. One of seven eyes (14\%) treated with vitrectomy had a poor visual outcome (defined as $<20 / 400$ ) compared with one of five $(20 \%)$ eyes treated with intravitreal antimicrobials alone. During follow-up, all 12 eyes had progression of lens opacification and five of 12 (42\%) eyes underwent cataract surgery with posterior chamber intraocular lens placement.

Conclusion: In phakic patients, successful treatment of endophthalmitis can be achieved while preserving the uninvolved crystalline lens. Future cataract surgery with posterior chamber intraocular lens placement can be accomplished in many of these patients.

Keywords: phakic eyes, cataract surgery, intraocular, intravitreal

\section{Introduction}

Endophthalmitis is characterized by severe intraocular inflammation caused by introduction of microorganisms, and is characterized by pain, conjunctival congestion, and reduced vision. Despite appropriate therapeutic intervention, endophthalmitis frequently results in severe visual loss. Since cataract surgery was the most commonly performed type of ocular surgery, this setting is the most frequent etiology in clinical practice. However, endophthalmitis may also develop in phakic eyes through endogenous spread, after trauma, or after other ophthalmic surgery. ${ }^{1-6}$ In phakic patients with endophthalmitis, the crystalline lens is frequently removed in the setting of lenticular abscess, disruption of lens capsule, total lens opacity, or in eyes with severe inflammation causing nonclearing fibrin in the anterior chamber. ${ }^{3,7,8}$ In 1991, a similar study of 12 patients from our institution reported the management of 
endophthalmitis while preserving the uninvolved crystalline lens. ${ }^{9}$ In the current more contemporary study, the course of infection in phakic eyes with endophthalmitis is reviewed in which the crystalline lens was preserved and compared with the previous report.

\section{Methods}

The study protocol was approved by the institutional review board of the University of Miami Leonard School of Medicine, subcommittee for the protection of human subjects. Microbiological and clinical records were reviewed for all patients treated at Bascom Palmer Eye Institute between January 1995 and June 2009. Patients with endophthalmitis managed by lensectomy and vitrectomy were excluded.

Intraocular fluid specimens from these patients were plated directly on to chocolate agar, $5 \%$ sheep blood agar, and Sabouraud agar. Chocolate and blood agars were incubated at $35^{\circ} \mathrm{C}$ for up to 2 weeks. Sabouraud agars were incubated at $35^{\circ} \mathrm{C}$ for 72 hours and then at $25^{\circ} \mathrm{C}$ for up to 2 weeks. Colonies suggestive of fungal growth were evaluated by Giemsa, Calcofluor white, and slice culture to detect microscopic morphology and characteristic conditions.
Cultures were considered positive when there was growth of the same organism on two or more solid media at the inoculation site, or when the organism grew on one culture media and was noted on a stained smear (Gram, Giemsa, or Gomori methenamine silver). Treatment and management decisions were made by the individual treating physicians without a predefined study protocol. Demographic information, etiology of infection, causative organism, treatment modalities, pretreatment and post-treatment lens status, visual acuity outcome, and duration of follow-up were evaluated.

\section{Results}

Twelve phakic eyes of 11 patients with culture-positive endophthalmitis treated without removal of the uninvolved crystalline lens were identified. The 11 patients ranged in age from 32 to 76 years. Five patients were female and six were male. Six patients had involvement of the right eye, four had involvement of the left eye, and one had involvement of both eyes. Etiology of infection was endogenous in six eyes, a post-glaucoma filtering procedure in five eyes, postvitrectomy in one eye, and post-traumatic in one eye. Isolates included fungi in seven eyes, followed by Gram-positive

Table I Demographic information, etiology of infection, treatment and causative organism in a phakic endophthalmitis series

\begin{tabular}{|c|c|c|c|c|c|c|c|c|c|}
\hline \multirow{2}{*}{ Patient } & \multicolumn{3}{|c|}{$\begin{array}{l}\text { Gender, } \\
\text { age (years), } \\
\text { eye }\end{array}$} & \multirow{2}{*}{$\begin{array}{l}\text { Category } \\
\text { Endogenous }\end{array}$} & \multirow{2}{*}{$\begin{array}{l}\begin{array}{l}\text { Predisposing } \\
\text { factor }\end{array} \\
\text { Foot ulcer }\end{array}$} & \multirow{2}{*}{$\begin{array}{l}\text { Anterior } \\
\text { chamber } \\
\text { reaction }\end{array}$} & \multirow{2}{*}{$\begin{array}{l}\text { Vitritis } \\
2+\end{array}$} & \multirow{2}{*}{$\begin{array}{l}\text { Treatment/intraocular } \\
\text { therapy } \\
\text { PPV, ampho, vanc, ceftaz }\end{array}$} & \multirow{2}{*}{$\begin{array}{l}\text { Culture } \\
\text { result }\end{array}$} \\
\hline & $M$ & 58 & L & & & & & & \\
\hline 2 & $\mathrm{~F}$ & 64 & L & Endogenous & ICU patient & $3+$ & $3+$ & $\begin{array}{l}\text { PPV, ampho, dex, } \\
\text { oral fluconazole }\end{array}$ & Candida albicans \\
\hline 3 & $\mathrm{~F}$ & 50 & $\mathrm{R}$ & Endogenous & $\begin{array}{l}\text { Osteomyelitis, } \\
\text { indwelling catheter }\end{array}$ & $3+$ & $3+$, infiltrates & Ampho, oral fluconazole & Candida albicans \\
\hline \multirow[t]{2}{*}{4} & $M$ & 56 & $\mathrm{R}$ & Endogenous & Colorectal surgery & $3+$ & $3+$ & $\begin{array}{l}\text { Ampho, intravenous } \\
\text { fluconazole, } \\
\text { PPV (after } 2 \text { months) }\end{array}$ & Candida albicans \\
\hline & & & L & Endogenous & Colorectal surgery & $2+$ & $2+$, infiltrates & $\begin{array}{l}\text { PPV, ampho, intravenous } \\
\text { fluconazole }\end{array}$ & Candida albicans \\
\hline 5 & $M$ & 43 & $\mathrm{R}$ & Endogenous & IVDA & $3+$ & $3+$ & $\begin{array}{l}\text { PPV, ampho, vanc, ceftaz, } \\
\text { oral fluconazole }\end{array}$ & Candida albicans \\
\hline 6 & M & 32 & $\mathrm{R}$ & Trauma & Dust blown in eye & $3+$ & $\mathrm{I}+$ & PPV, vori & Candida albicans \\
\hline 7 & $\mathrm{~F}$ & 72 & L & Postoperative & $\begin{array}{l}\text { Status post glaucoma } \\
\text { filtering surgery }\end{array}$ & $3+$ & Trace & Vanc, ceftaz, dex & $\begin{array}{l}\text { Moraxella } \\
\text { species }\end{array}$ \\
\hline 8 & $M$ & 50 & $\mathrm{R}$ & Postoperative & $\begin{array}{l}\text { Status post glaucoma } \\
\text { filtering surgery }\end{array}$ & $3+$ & $\mathrm{I}+$ & $\begin{array}{l}\text { Gent, intravitreal } \\
\text { cefazolin }\end{array}$ & $\begin{array}{l}\text { Haemophilus } \\
\text { influenzae }\end{array}$ \\
\hline 9 & $\mathrm{~F}$ & 62 & L & Postoperative & $\begin{array}{l}\text { Status post glaucoma } \\
\text { filtering surgery }\end{array}$ & & $3+$ & PPV, vanc, ceftaz, dex & $\begin{array}{l}\text { Staphylococcus } \\
\text { aureus }\end{array}$ \\
\hline 10 & $\mathrm{~F}$ & 76 & $\mathrm{R}$ & Postoperative & $\begin{array}{l}\text { Status post glaucoma } \\
\text { filtering surgery }\end{array}$ & $4+$ & & Gent, vanc, ceftaz, dex & $\begin{array}{l}\text { Coagulase- } \\
\text { negative } \\
\text { Staphylococcus }\end{array}$ \\
\hline II & $M$ & 71 & $\mathrm{R}$ & Postoperative & $\begin{array}{l}\text { Status post PPV for } \\
\text { NCVH }\end{array}$ & $\begin{array}{l}\text { Large } \\
\text { hypopyon }\end{array}$ & Vit hemorrhage & Vanc, ceftaz, dex & $\begin{array}{l}\text { Staphylococcus } \\
\text { epidermidis }\end{array}$ \\
\hline
\end{tabular}

Note: Anterior chamber reaction, vitritis and chorioretinitis are as noted by the treating physician.

Abbreviations: ICU, intensive care unit; PPV, pars plana vitrectomy; vanc, intravitreal vancomycin; gent, intravitreal gentamicin; ceftaz, intravitreal ceftazidime; ampho, intravitreal amphotericin B; vori, intravitreal voriconazole; dex, intravitreal dexamethasone; $\mathrm{NCVH}$, nonclearing vitreous hemorrhage. 
bacteria in three and Gram-negative bacteria in two eyes (Table 1). Seven eyes (58\%) were treated with pars plana vitrectomy and injection of intravitreal antimicrobials. Five eyes $(42 \%)$ were treated with intravitreal injection of antimicrobials alone (Table 1). After treatment, 12 of 12 eyes had progression of lens opacification at last follow-up (Table 2). With an average follow-up of 39 months, nine of 12 eyes $(75 \%)$ had visual acuity outcomes $\geq 20 / 80$. Visual acuity of 20/80 or better was achieved in five of seven $(71 \%)$ eyes treated with vitrectomy and four of five $(80 \%)$ of eyes treated with injection of antimicrobials alone. A visual acuity of $20 / 80$ or better was achieved in four of six $(67 \%)$ eyes with endogenous endophthalmitis, four of five (80\%) eyes with postoperative endophthalmitis, and all (1/1) eyes with post-traumatic endophthalmitis. Poor visual acuity of $<20 / 400$ was noted in two (17\%) eyes. One of five $(20 \%)$ eyes treated with intraocular antimicrobials alone had a visual outcome $\leq 20 / 400$ compared with one of seven (14\%) eyes that underwent vitrectomy. Cataract surgery with posterior chamber intraocular lens placement was performed in five of $12(42 \%)$ eyes. All cataract surgeries were noted to be without complications, such as capsular rupture and excessive postoperative inflammation.

\section{Discussion}

Published evidence is limited regarding the management of endophthalmitis while preserving the uninvolved crystalline lens. The current study, along with the prior case series from the same institution, creates the largest experience from a single institution on this subject. ${ }^{9}$ In the current study, all patients with endogenous endophthalmitis were culture-positive for Candida albicans. The majority of these eyes had a favorable visual outcome (Figure 1). As reported in previous studies, Candida is a more common cause than molds in patients with endogenous endophthalmitis, and is associated with a more favorable visual outcome ${ }^{1,10}$ Candida is generally less invasive than molds and is usually responsive to amphotericin B. ${ }^{11}$ In this series, intravitreal amphotericin was the most common antifungal used.

In the current study, poor visual outcomes occurred with equivalent frequency in eyes undergoing vitrectomy and in eyes receiving only intraocular antibiotics. Patient 2 , with endophthalmitis from endogenous $C$. albicans, was a long-term intensive care unit patient in very poor general health. Patient 11 developed endophthalmitis caused by Staphylococcus epidermidis after vitrectomy for a nonclearing vitreous hemorrhage. The infection was treated with intravitreal antibiotics but without repeat vitrectomy. Visual acuity after subsequent cataract extraction improved to $20 / 80$.

In the earlier study, we reported that eyes infected with virulent organisms, including Staphylococcus aureus and Streptococcus spp and treated with intravitreal antibiotics alone tended to have worse visual outcomes. Presence of virulent organisms in these cases probably accounts for poor visual outcome as published in our previous reports and underscores the importance of early vitrectomy in these cases. ${ }^{12-14}$

The advantage of retaining the crystalline lens is to allow conventional cataract extraction and posterior chamber intraocular lens placement at a later date (Figure 2). Placing an intraocular lens is not possible in the presence of

Table 2 Pretreatment and post-treatment lens status, visual acuity results, and duration of follow-up in phakic endophthalmitis series

\begin{tabular}{|c|c|c|c|c|c|c|}
\hline Patient & $\begin{array}{l}\text { Pretreatment } \\
\text { lens status }\end{array}$ & $\begin{array}{l}\text { Final lens status } \\
\text { (before CE) }\end{array}$ & $\begin{array}{l}\text { Presenting } \\
\text { visual acuity }\end{array}$ & $\begin{array}{l}\text { Final } \\
\text { visual acuity }\end{array}$ & $\begin{array}{l}\text { Follow-up } \\
\text { (months) }\end{array}$ & Comment \\
\hline $\mathrm{I}$ & Clear & $\mathrm{I}+\mathrm{NS}$ & $20 / 30$ & $20 / 25$ & 12 & Chronic peripheral RD \\
\hline 2 & Clear & $3+\mathrm{PSC}$ & $20 / 200$ & NLP & 6 & Recurrent RD \\
\hline 3 & Clear & $\mathrm{I}+\mathrm{NS}$ & $20 / 80$ & $20 / 20$ & 12 & \\
\hline \multirow[t]{2}{*}{4} & Clear & $4+\mathrm{NS}$ & $20 / 100$ & $20 / 100$ & 23 & CE at 9 months macular scar \\
\hline & Clear & $2+\mathrm{NS}$ & $20 / 50$ & $20 / 30$ & 23 & \\
\hline 5 & Trace NS & $\mathrm{I}+\mathrm{NS}$ & HM & $20 / 80$ & 51 & \\
\hline 6 & Clear & Trace NS & $20 / 30$ & $20 / 20$ & 7 & \\
\hline 7 & $2+N S$ & $3+\mathrm{NS}$ & $20 / 400$ & $20 / 25$ & 53 & CE after 22 months \\
\hline 8 & I+PSC & $2+\mathrm{NS}, 2+\mathrm{PSC}$ & $20 / 200$ & $20 / 30$ & 96 & \\
\hline 9 & $\mathrm{I}+\mathrm{NS}$ & $3+\mathrm{NS}, 3+\mathrm{PSC}$ & LP & $20 / 60$ & 83 & CE after 10 months \\
\hline 10 & $\mathrm{I}+\mathrm{NS}$ & $2+\mathrm{NS}$ & $20 / 400$ & $20 / 40-2$ & 73 & CE after 12 months \\
\hline 11 & $\mathrm{I}+\mathrm{NS}$ & $3+\mathrm{NS}, 3+\mathrm{PSC}$ & $\mathrm{HM}$ & $6 / 200$ & 31 & $\begin{array}{l}\text { CE after } 27 \text { months; macular scar, } \\
\text { band keratopathy }\end{array}$ \\
\hline
\end{tabular}

Note: Lens status is as noted by the treating physician.

Abbreviations: CE, cataract extraction; NS, nuclear sclerosis; PSC, posterior subcapsular cataract; HM, hand motion; LP, light perception; NLP, no light perception; RD, retinal detachment. 


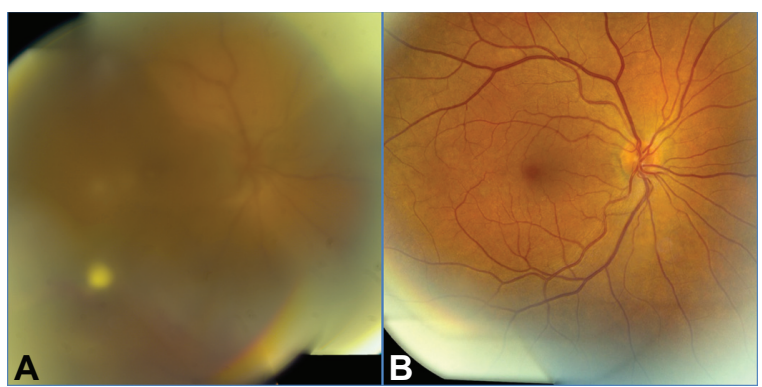

Figure I Patient 3, a 50-year-old female with a history of osteomyelitis and chronic intravenous antibacterial treatment. (A) Fundus at presentation. Visual acuity 20/80. Systemic candidemia and endogenous Candida albicans endophthalmitis OD. (B) Fundus II months after presentation. Patient treated with intravitreal amphotericin B and systemic fluconazole. Visual acuity 20/20.

intraocular infection. Another potential advantage of leaving the crystalline lens is the relatively increased half-life of intraocular administered antibiotics in phakic compared with aphakic eyes. ${ }^{15,16}$ This may reduce the need for repeat intraocular injection of antibiotics.

Because this is a retrospective review, the experience of the previous report from our center of improved visual outcomes in eyes undergoing vitrectomy compared with eyes treated without vitrectomy may have influenced treatment decisions (Table 3). Patients infected with the most virulent organisms were treated with prompt vitrectomy and intravitreal antibiotics, and the overall rate of good visual outcomes was improved compared with the previous report from our center. While this series is not large enough to draw statistically significant conclusions, excellent visual outcomes were seen in eyes treated with intravitreal antimicrobials with and without vitrectomy.

In the current study, good visual outcomes were often achieved in the treatment of endophthalmitis with preservation of the uninvolved crystalline lens. Removal of uninvolved crystalline lens may not be necessary unless lens

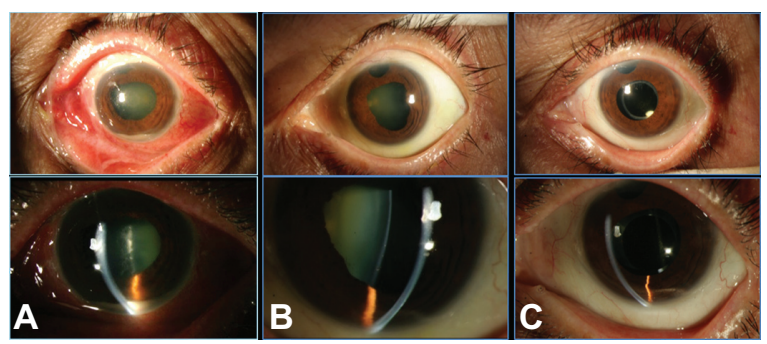

Figure 2 Patient 7, a 72-year-old female with history of glaucoma filtering surgery OS 8 months prior to presentation. (A) Slit lamp at presentation. Visual acuity 20/400. Culture positive for Moraxella species. (B) Slit lamp 2 months after presentation. Patient treated with intravitreal vancomycin, ceftazidime, and dexamethasone. Visual acuity 20/25. (C) Slip lamp 22 months after presentation, 4 months after uncomplicated phaco/intraocular lens implantation OS. Visual acuity 20/25.
Table 3 Clinical characteristics and outcome comparison between case series

\begin{tabular}{lll}
\hline & Huang et al $^{9}$ & Current study \\
\hline $\begin{array}{l}\text { Study years } \\
\text { Number of cases }\end{array}$ & $1980-1989$ & $1995-2009$ \\
$\begin{array}{l}\text { Etiology (number of cases) } \\
\quad \text { Endogenous }\end{array}$ & 12 \\
$\quad$ Postoperative & 7 & 6 \\
$\quad$ Traumatic & 12 & 5 \\
Treatment (number of cases) & & 1 \\
$\quad$ PPV + intravitreal abx & 7 & \\
$\quad$ Intravitreal abx & 5 & 7 \\
VA outcomes (number of cases) & & 5 \\
$\quad \geq 20 / 80$ & 6 & 9 \\
$\quad 20 / 100-20 / 400$ & 1 & 1 \\
$\quad<20 / 400$ & 5 & 2 \\
CE + IOL during follow-up & 2 & 5 \\
\hline
\end{tabular}

Abbreviations: IOL, intraocular lens; CE, cataract extraction; PPV, pars plana vitrectomy; VA, visual acuity.

opacity represents a violation of an intact lens capsule or the cloudy lens precludes a pars plana vitrectomy.

\section{Acknowledgment}

The authors acknowledge funding received from the National Institute of Health Center (grant P30-EY014801) and an unrestricted grant from the University of Miami from Research to Prevent Blindness, New York.

\section{Disclosure}

The authors declare that they have no conflict of interest in this work.

\section{References}

1. Schiedler V, Scott IU, Flynn HW Jr, et al. Culture-proven endogenous endophthalmitis: clinical features and visual acuity outcomes. Am J Ophthalmol. 2004;137:725-731.

2. Lieb DF, Scott IU, Flynn HW Jr, Miller D, Feuer WJ. Open globe injuries with positive intraocular cultures: factors influencing final visual acuity outcomes. Ophthalmology. 2003;110:1560-1566.

3. Leng T, Miller D, Flynn HW Jr, Jacobs DJ, Gedde SJ. Delayed-onset bleb-associated endophthalmitis (1996-2008): causative organisms and visual acuity outcomes. Retina. 2011;31:344-352.

4. Wykoff CC, Flynn HW Jr, Miller D, Scott IU, Alfonso EC. Exogenous fungal endophthalmitis: microbiology and clinical outcomes. Ophthalmology. 2008;115:1501-1507.

5. Eifrig CW, Scott IU, Flynn HW Jr, Smiddy WE, Newton J. Endophthalmitis after pars plana vitrectomy: Incidence, causative organisms, and visual acuity outcomes. Am J Ophthalmol. 2004;138:799-802.

6. Gelender H, Flynn HW Jr, Mandelbaum SH. Bacterial endophthalmitis resulting from radial keratotomy. Am J Ophthalmol. 1982;93:323-326.

7. Kaushik S, Ram J, Dogra MR, et al. Traumatic lens abscess with chronic endophthalmitis successfully treated with pars plana lensectomy and vitrectomy. Ophthalmic Surg Lasers. 2001;32:239-242.

8. Flynn HW Jr, Scott IU, Brod RD, Han DP. Current management of endophthalmitis. Int Ophthalmol Clin. 2004;44:115-137. 
9. Huang SS, Brod RD, Flynn HW Jr. Management of endophthalmitis while preserving the uninvolved crystalline lens. Am J Ophthalmol. 1991;112:695-701.

10. Essman TF, Flynn HW Jr, Smiddy WE, et al. Treatment outcomes in a 10 -year study of endogenous fungal endophthalmitis. Ophthalmic Surg Lasers. 1997;28:185-194.

11. Rao NA, Hidayat AA. Endogenous mycotic endophthalmitis: variations in clinical and histopathological changes in candidiasis compared with aspergillosis. Am J Ophthalmol. 2001;132:244-251.

12. Major JC Jr, Engelbert M, Flynn HW Jr, et al. Staphylococcus aureus endophthalmitis: antibiotic susceptibilities, methicillin resistance, and clinical outcomes. Am J Ophthalmol. 2010;149:278-283.
13. Yoder DM, Scott IU, Flynn HW Jr, Miller D. Endophthalmitis caused by Haemophilus influenzae. Ophthalmology. 2004;111:2023-2026.

14. Miller JJ, Scott IU, Flynn HW Jr, et al. Endophthalmitis caused by Streptococcus pneumoniae. Am J Ophthalmol. 2004;138:231-236.

15. Shaarawy A, Meredith TA, Kincaid M, et al. Intraocular injection of ceftazidime. Effects of inflammation and surgery. Retina. 1995;15: 433-438.

16. Aguilar HE, Meredith TA, el-Massry A, et al. Vancomycin levels after intravitreal injection. Effects of inflammation and surgery. Retina. 1995; $15: 428-432$
Clinical Ophthalmology

\section{Publish your work in this journal}

Clinical Ophthalmology is an international, peer-reviewed journal covering all subspecialties within ophthalmology. Key topics include: Optometry; Visual science; Pharmacology and drug therapy in eye diseases; Basic Sciences; Primary and Secondary eye care; Patient Safety and Quality of Care Improvements. This journal is indexed on

Submit your manuscript here: http://www.dovepress.com/clinical-ophthalmology-journal

\section{Dovepress}

PubMed Central and CAS, and is the official journal of The Society of Clinical Ophthalmology (SCO). The manuscript management system is completely online and includes a very quick and fair peer-review system, which is all easy to use. Visit http://www.dovepress.com/ testimonials.php to read real quotes from published authors. 